FERMILAB-Conf-97/248

\title{
Experience with the Procurement of Ferrite and Temperature Compensator for Permanent Magnets for Accelerators
}

\author{
William B. Fowler, Bruce C. Brown and James Volk \\ Fermi National Accelerator Laboratory \\ P.O. Box 500, Batavia, Illinois 60510
}

July 1997

Presented at the Particle Accelerator Conference, PAC ‘97, Vancouver, Canada, May 12-16, 1997 


\section{Disclaimer}

This report was prepared as an account of work sponsored by an agency of the United States Government. Neither the United States Government nor any agency thereof, nor any of their employees, makes any warranty express or implied or assumes any legal liability or responsibility for the accuracy, completeness or usefulness of any information. apparatus. product or process disclosed. or represents that its use would not infringe privately owned rights. Reference herein to any specific commercial product, process or service by trade name, trademark, manufacturer or otherwise, does not necessarily constitute or imply its endorsement, recommendation or favoring by the United States Government or any agency thereof. The views and opinions of authors expressed herein do not necessarily state or reflect those of the United States Government or any agency thereof.

\section{Distribution}

Approved for public release: further dissemination unlimited. 


\title{
EXPERIENCE WITH THE PROCUREMENT OF FERRITE AND TEMPERATURE COMPENSATOR FOR PERMANENT MAGNETS FOR ACCELERATORS
}

\author{
William B.Fowler, Bruce Brown, and James Volk, Fermi National Accelerator \\ Laboratory*, P.O. Box 500 Batavia, IL 60510
}

\begin{abstract}
The use of permanent magnets for transporting the $8 \mathrm{GeV}$ proton beam from the Fermilab Booster to the new Fermilab Main Injector accelerator has been implemented and the magnets for a new $8 \mathrm{GcV}$ ring to be installed in the Main Injector tunnel for increasing the luminosity of pbar/p collisions in the Tevatron are about to start being produced. Strontium oxide ferrite was selected for the magnets due to it's low cost and satisfactory magnetic properties for the 1.5 kilogauss fields required in the 2 -inch gap magnets. Fermilab has received 96,000 pounds of ferrite and by working with the Vendor (HITACHI, Edmore, MI) improved uniformity of Residual Induction (Br) has reached 3905 gauss $\pm 0.65 \%$. Further details are given in the paper. Overcoming the magnetic field variation when the temperature of the magnets changes is accomplished by incorporation of approximately $30 \%$ nickel steel alloy. The ferrite changes approximately $-0.2 \%$ per degree $\mathrm{C}$, which is compensated for by the $13 \%$ by volume of compensator alloy incorporated in the magnet. Fourteen thousand $(14,000)$ pounds of this material has been received and in order to obtain sufficient uniformity we mixed equal amounts from each batch into each magnet. Results of this process are given in the paper.
\end{abstract}

\section{INTRODUCTION}

Fermilab has added to the Main Injector Project a fixed $8 \mathrm{GeV}$ storage ring called the Recycler. It is to be located in the Main Injector tunnel directly above the Main Injector magnets near the ceiling of the tunnel. The construction schedule calls for the installation of the Recycler ring during the completion of the Main Injector. This is made possible by the use of permanent magnets. The primary benefits of the Recycler are:

1) Facilitates the attainment of Tevatron collider goals by relieving the Antiproton Source of the responsibility for maintaining high stacking rates at high stacks.

2) Provides potential for a factor of two in Tevatron Luminosity by allowing recovery of unspent antiprotons at the end of stores.

Since there was very little experience in the use of permanent magnets at Fermilab it was decided to convert the $8 \mathrm{GeV}$ beam transport line from the Booster to the Main Injector from electro magnets to permanent magnets similar to those required by the Recycler. The $8 \mathrm{GeV}$ line of about 100 magnets required 80,000 pounds of Ferrite.

\section{FERRITE}

Type 8 Strontium Ferrite was chosen based on cost, availability and stability. There are three major manufactures of Strontium Ferrite in the United States each with a capacity of several million pounds per year. The Material is used in automobiles, speakers and lifting devices. Recently it has been used in permanent magnet magnetic imaging applications. A standard brick size was selected and in order to incorporate the bricks into the Recycler magnet design attention was given to dimensional tolerances. Fig. 1 shows the variation of the six inch length dimension of a brick in a typical sample of 40 
bricks. Fig. 2 shows the variation in the four inch width dimension in the same sample of $\mathbf{4 0}$ bricks and Fig. 3 the variation of the one inch thickness dimension.

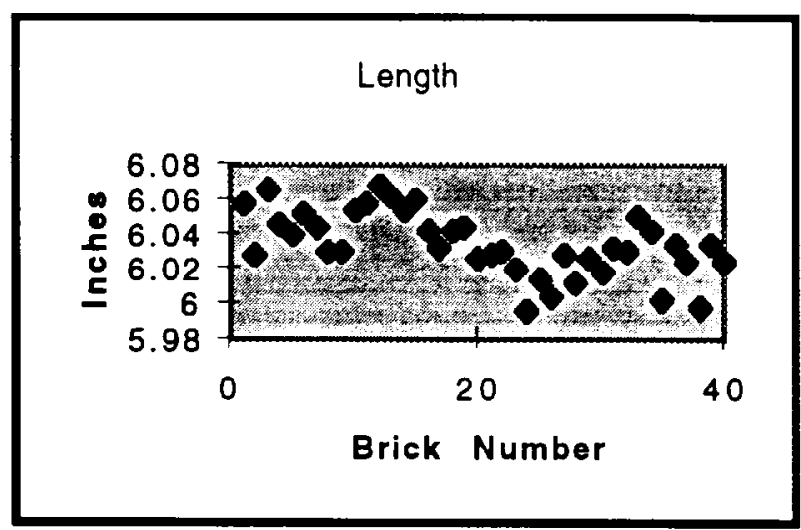

Fig. 1 Variation in Brick length for 40 Bricks

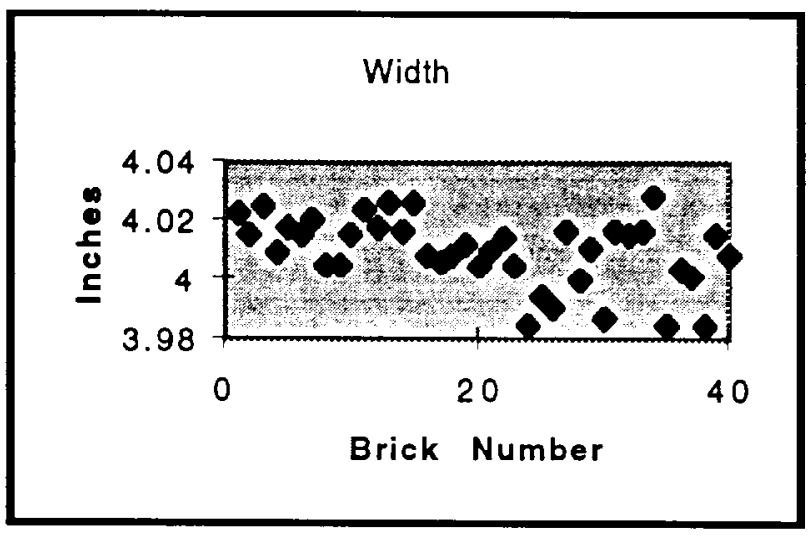

Fig. 2 Variation in Brick width for 40 Bricks

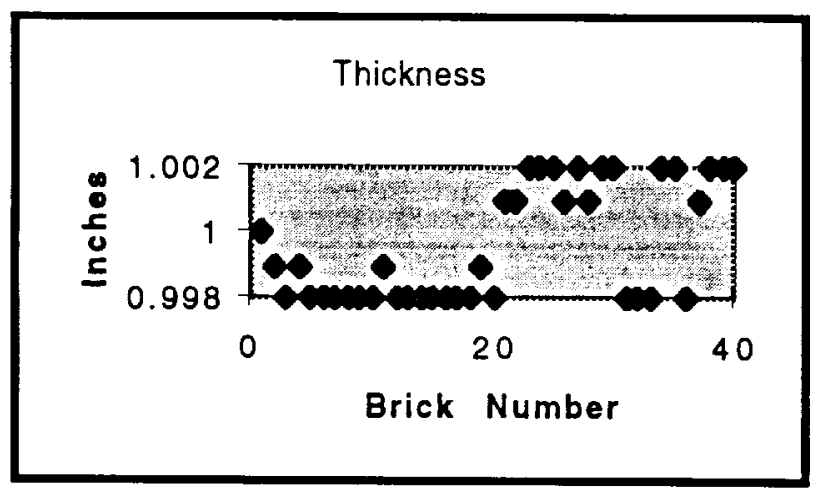

Fig, 3 Variation in Brick thickness for 40 Bricks
Table I presents this data in comparison with the specification. In order to achieve the smallest possible dimensional variation a three cavity die was constructed by the successful Vendor, HITACHI METALS(Edmore, MI) and all of the Strontium Ferrite bricks for Fermilab are produced with this die. Of interest to note is that the production rate with this three cavity die is three bricks every two minutes and 15 seconds. This yields about 1600 bricks per 20 hour day.

Table 1: Specification vs. Measurements

Brick Dimensions in inches

\begin{tabular}{|l|r|l|}
\hline Specifications & & \\
\hline Length & 6.000 & +.090 \\
\hline & & -.090 \\
\hline Width & 4.000 & +.060 \\
\hline & & -.060 \\
\hline Thickness & 1.000 & +.005 \\
\hline & & -.005 \\
\hline & & \\
\hline 40 Brick Measurements & & \\
\hline Length & 6.000 & +.070 \\
\hline & & -.000 \\
\hline Width & 4.000 & +.030 \\
\hline & & -.015 \\
\hline Thickness & 1.000 & +.002 \\
\hline & & -.002 \\
\hline
\end{tabular}

One note of caution in using the tighter tolerances as determined from the 40 brick data should be expressed. This restricted set of bricks did not include the entire range of possible dimensions over the production run of 70,000 bricks so it may not correspond to the maximum variation one might encounter. However the important conclusion is that it is probably not necessary to use the range of the generally acoepted specification if a single die is used and by measuring the total range of brick dimensions a tighter tolerance can be used for the permanent magnet design.

Recycler magnets are required to have an integrated field strength accuracy that can only be achieved by adjusting the amount of Ferrite in each magnet after it is constructed. This then overcomes the inherent variation in Ferrite magnetic properties. However in order to minimize the magnitude of 
the trimming operation it is beneficial to reduce the Ferrite brick differences in $\mathrm{Br}$ and $\mathrm{Hci}$ to the extent possible. Type 8 Ferrite nominal $\mathrm{Br}$ is 3850 Gauss with 3050 Gauss for Hci. The accepted tolerance on $\mathrm{Br}$ is $\pm 5 \%$ and $\pm 8 \%$ on $\mathrm{Hci}$. By restricting the brick processing to the more uniform temperature portion of the kiln during the Sintering operation the variation in $\mathrm{Br}$ has been reduced to $\pm 0.65 \%$. Of interest is the tracking studies that Fermilab has carried out from batch to batch of Ferrite received. Fig.'s 4 and 5 summarize magnetic tests performed by the Vendor on a randomly selected brick from each 400 bricks shipped. Five shipments are shown. The two earliest consisted of 10 tests from a total of 4000 bricks each. The three latest shipments contained 6000 bricks with 15 tests each.

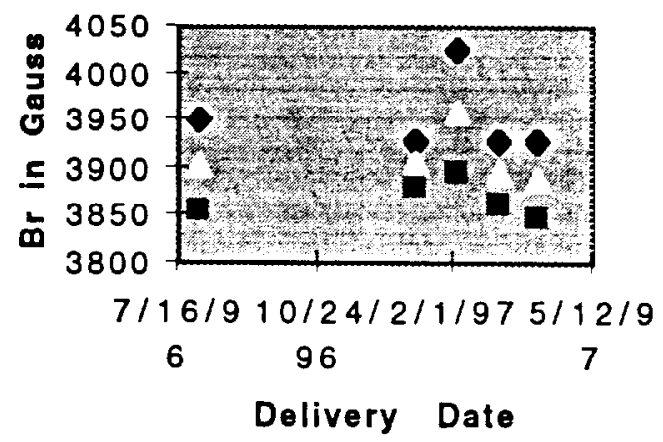

Fig. 4 Trend Analysis of Ferrite Bricks Received by Fermilab $(\mathrm{Br})$

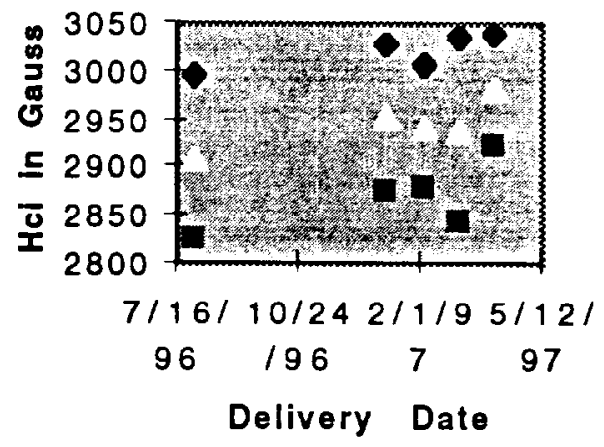

Fig. 5 Trend Analysis of Ferrite Bricks Received by Fermilab (Hci)

\section{COMPENSATOR}

Overcoming the Recycler magnets change in magnetic field due to unavoidable tunnel temperature changes is accomplished by incorporating $13 \%$ by volume of $30 \%$ nickel steel alloy. Recent measurements of the temperature coefficient of three separate Ferrite bricks showed $-0.187 \%, 0.184 \%$ and $-0.189 \%$ per degree $C$. Therefore some of the magnetic field change can come from variation in the Ferrite properties. Compensator alloy measurements supplied by the Vendor (TELCON, Crawley, England) show a variation of $\Delta B / \Delta T$ of 61 to 78 Gauss/degree $C$. These measurements are at 50 Gauss. Recent measurements at 1500 Gauss, the field that the Recycler magnets operate at were similar. The variation seems to depend on the work hardening that occurs after a final heat treatment. We have avoided the complication of the need to change the percentage of compcnsator in each magnet by mixing compensator batches. the mixing included mixing different melts of material and also mixing compensator from the ends and middle of a roll of material. For instance some measurements from the two ends of a roll are identical while in other cases the measurement from the two ends of a roll vary by $10 \%$.

The Recycler permanent magnets are primarily combined function magnets, that is they combine a dipole field and a quadrupole field by using tapered pole tips. The compensator is incorporated as two inch wide by six inch long strips each 50 mils thick. Per four inch brick there are ten compensator strips. Since these packets of compensator are assembled into the magnet as it is constructed it is important to not have to adjust the number of strips. To do so requires the magnet to be taken apart. Investigations are continuing to be sure that our mixing procedure avoids this complication even though during the last stages of $8 \mathrm{GeV}$ beam line magnet production no magnets had to be redone.

* Operated by Universities Research Association under contract to the United States Department of Energy 